DOI: $10.30612 /$ re-ufgd.v4i8.7664

\title{
A ÍNTERI JR. E O MOVIMENTO EMPRESA JÚNIOR COMO INSTRUMENTOS DO ECOSSISTEMA EMPREENDEDOR DO MATO GROSSO DO SUL
}

Ínteri Jr. and the Junior Enterprise Movement as tool of the Entrepreneurial Ecosystem of Mato

Grosso do Sul

Hermes Moreira Jr. ${ }^{1}$

Elis Poli Chiachio ${ }^{2}$

Renata Ruiz Simas ${ }^{3}$

Recebido em 09/03/2017

Aceito em 15/12/2017

Resumo: O presente artigo se propõe a discutir como as empresas júniores são relevantes no debate sobre ecossistemas empreendedores. Como foco teremos a Ínteri Jr., Empresa Júnior do curso de Relações Internacionais da Universidade Federal da Grande Dourados (UFGD). Através da apresentação de sua trajetória institucional e de consultorias prestadas, abordaremos o funcionamento do Ecossistema Empreendedor do Mato Grosso do Sul. O movimento empresa júnior no estado começou de fato em 2012, com a caracterização da Ínteri Jr. como sendo a primeira empresa júnior na região a atuar em rede. Após sua fundação, outros universitários de outros cursos foram inspirados e novas empresas júniores começaram a surgir dentro dessa mesma perspectiva, o que levou à fundação da Federação de Empresas Júniores do Mato Grosso do Sul. Nesse contexto será apresentado que, a economia tradicional da região não deve ser tomada como fator limitante das possibilidades de desenvolvimento econômico e as empresas júniores do estado vieram justamente para potencializar este desenvolvimento de forma acessível e de qualidade.

Palavras-chave: Empreendedorismo. Ecossistema Empreendedor. Movimento Empresa Júnior.

Abstract: This article aims to discuss how college start-ups are relevant in the debate on entrepreneurial ecosystems. We will have look on Ínteri Jr., college start-up of the UFGD's International Relations course. Through the presentation of its institutional trajectory and consulting services provided, we will cover the operation of the Entrepreneurial Ecosystem of Mato Grosso do Sul. The college start-up movement in the state was born in 2012, with the characterization of Ínteri Jr. as being the first college start-up in the region to act in network. After its foundation, other university students were inspired and new junior companies began to emerge within the same perspective, to create the Federation of College Start-Ups of Mato Grosso do Sul. In this context, it will be presented that the traditional economy of the region should not be taken as a limiting factor of the possibilities to economic development and the college start-ups came precisely to enhance this development.

Key-words: Entrepreneurship. Entrepreneurial ecosystem. College start-up movement.

$1 \quad$ Professor do curso de Relações Internacionais da Universidade Federal da Grande Dourados. É orientador da Ínteri Jr. (hermesmoreira@ufgd.edu.br)

2 Graduada em Relações Internacionais pela Universidade Federal da Grande Dourados. Foi membro da Diretoria da FEJEMS. (elispolichiachio@gmail.com)

3 Graduada em Relações Internacionais pela Universidade Federal da Grande Dourados. Foi membro da Confederação Brasileira de Empresas Júniores/Brasil Júnior. (ruizsrenata@gmail.com) 


\section{Introdução}

Um ecossistema, conforme a Biologia, é um ambiente onde diversos atores interagem para a sua sobrevivência, interação e desenvolvimento. Do mesmo modo, em nossa sociedade, essa interação existe e pode surgir com finalidades diversas. Neste artigo, abordaremos um ecossistema que é um ambiente dotado de atores que, em maior ou menor grau, contribuem para o desenvolvimento do empreendedorismo através de suas interações: o ecossistema empreendedor. Esse conceito é trazido pelo professor de Harvard, Daniel Isenberg, quando debate a formação e desenvolvimento de ecossistemas empreendedores em seu projeto "The Babson Entrepreneurship Ecosystem Project".

Isenberg defende que um ecossistema empreendedor possui esferas que o conforma, sendo elas: finanças, política, cultura, suporte, capital humano e mercados (Isenberg, 2011), conforme ilustrado abaixo. $\mathrm{O}$ conjunto e funcionamento pleno dessas esferas favorecem e aquecem um ecossistema empreendedor.

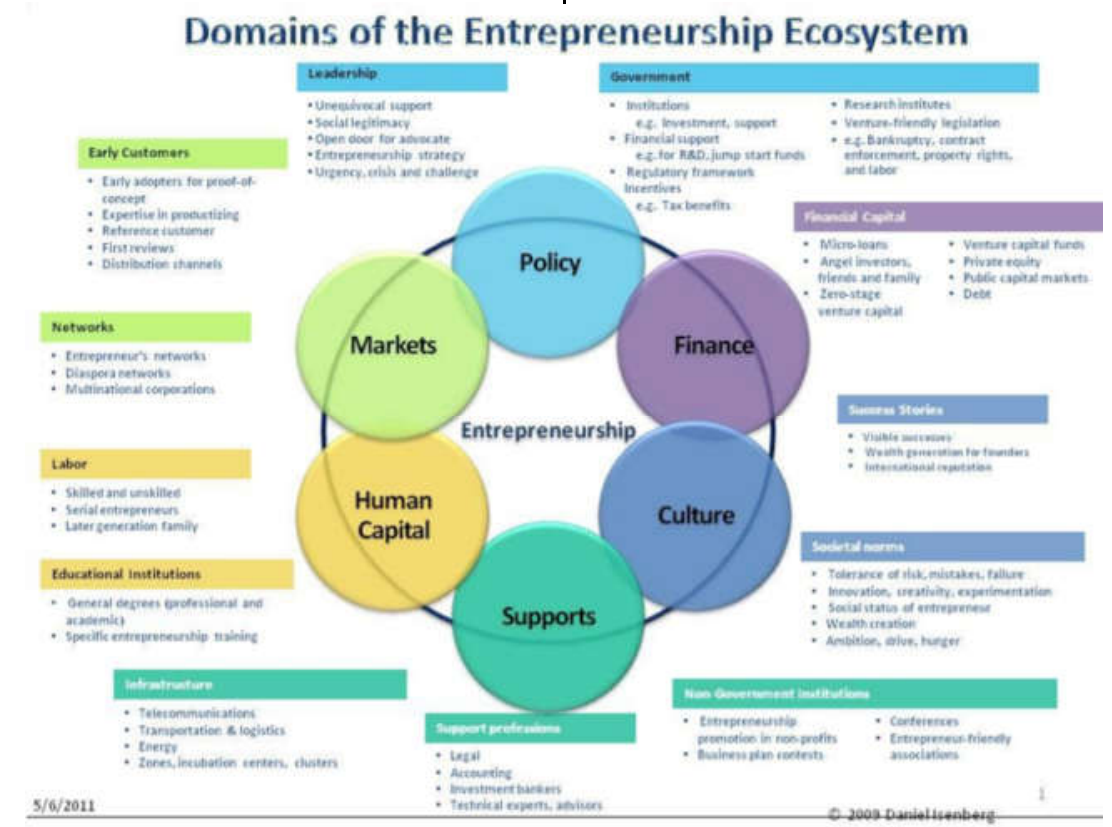

Fonte: ISENBERG, 2011.

Pensando nesses pilares, este artigo se propõe a discutir o ecossistema empreendedor do Mato Grosso do Sul através da ótica da Ínteri Jr.- Empresa Júnior de Relações Internacionais da Universidade
Federal da Grande Dourados. Analisaremos também o impacto das empresas júniores, associações civis sem fins lucrativos formadas no âmbito acadêmico nas quais seus membros, os universitários, prestam 
serviços de consultorias majoritariamente a micro e pequenos empreendedores, nos pilares de formação do ecossistema empreendedor de Daniel Isenberg apresentado acima. Para isso, discutiremos na primeira seção as bases teóricas que fundamentam a constituição de empresas júniores no interior das universidades e a gênese do Movimento Empresa Júnior no Brasil. Na sequência, apresentamos a trajetória de criação e institucionalização da Ínteri Júnior, a empresa júnior do curso de Relações Internacionais da UFGD. Por fim, analisamos a articulação do Movimento Empresa Júnior em rede no Mato Grosso do Sul e as potencialidades de sua atuação para o desenvolvimento regional.

\section{Empreendedorismo e Movimento}

\section{Empresa Júnior no Brasil}

O empreendedor, no senso comum, é entendido como aquele indivíduo que tem o seu negócio próprio e não depende de terceiros para operar. Todavia, segundo Schumpeter (1961), empreender é inovar a ponto de criar condições para uma radical transformação de um determinado setor, ramo de atividade ou território onde o empreendedor atua. Schumpeter também afirma que o empreendedor é aquele indivíduo que é capaz de ter sucesso com inovações. Ou seja, empreender vai além de abrir uma empresa e diz respeito a uma série de atitudes inovadoras de quem pratica o empreendedorismo e contribui para inovações e transformações radicais em seu entorno social (BRAGA MARTES, 2010).

Partindo desta definição, é possível que se empreenda independentemente da formação ou do setor profissional em que esteja atuando. Gifford Pinchot (1985) trouxe a ideia de intraempreendedorismo, ou seja, empreender internamente em uma organização. Nesse sentido, esse conceito tem sido usado para motivar e incentivar que cada vez mais os profissionais se sintam incomodados com a realidade e estejam sempre em busca de melhorias nos seus espaços de atuação de forma inovadora e criativa. Mais do que apenas empreendedorismo, fala-se sobre cultura empreendedora: a capacidade e o anseio de empreender na realidade a sua volta não importa qual seja ela. O empreendedor de fato não pode ser acomodado com a situação em que está inserido.

A Endeavor, maior organização que apoia empreendedores brasileiros e dissemina conteúdo sobre o tema, traça o perfil do empreendedor de impacto: otimista, curioso, corajoso, confiante, protagonista e perseverante em suas ações. Pessoas com essas características são cada vez mais procuradas no mercado e, aprender e colocar em prática tais atitudes ainda na formação do profissional tem se tornado importante para recrutadores de grandes organizações, que 
estão sempre em busca de jovens talentos que promovam a mudança em suas empresas.

No Brasil, a iniciativa para desenvolver jovens com esse perfil vem do Movimento Empresa Júnior, que se constitui a partir de 1988 com a abertura da primeira empresa júnior do país, a EJFGV (Empresa Júnior da Fundação Getúlio Vargas). O modelo, vindo da França, surgiu com a intenção de colocar em prática o que era aprendido em sala de aula e, ao mesmo tempo, impactar a sociedade com os projetos de consultoria das mais diversas áreas de atuação, desenvolvidos exclusivamente pelos alunos. Sendo assim, uma empresa júnior é uma empresa como qualquer outra, a diferença é que ela existe dentro da universidade e é gerida por acadêmicos, sob a supervisão de um professor orientador que auxilia nos projetos.

Recentemente, as empresas júniores passaram a ser amparadas pela Lei $13.267 / 2016$, que regulariza todas as atividades realizadas por essas organizações. Após a iniciativa pioneira da EJFGV, surgiram outras empresas júniores inicialmente nos estados de São Paulo, Bahia,
Minas Gerais e no Rio de Janeiro. Posteriormente foram se espalhando e o conceito se capilarizou a nível nacional, formando uma rede nacional de empresas júniores.

Atualmente, segundo a pesquisa Censo \& Identidade 2016, publicada pela Confederação Brasileira de Empresas Júniores (Brasil Júnior) ${ }^{1}$, atuaram 15.777 acadêmicos, com média de 20,9 anos, em 511 empresas júniores, espalhadas por 24 estados brasileiros e em mais de 120 universidades. Essas empresas júniores realizaram 4.865 projetos de consultoria e faturaram 11 milhões de reais, com um valor médio de 702 reais por empresário júnior da rede e 25 mil reais por empresa júnior confederada.

As empresas júniores se encontram em sua maioria no ensino público, com cerca de $70 \%$ das unidades estando em universidades federais e estaduais. Os cursos de graduação que mais cediam projetos desse tipo são as de Ciências Sociais Aplicadas e Engenharias, totalizando $58 \%$ das empresas júniores nesses ramos. Além desses, aparecem empresas júniores de comunicação, tecnológicas, ciências humanas e biológicas. 
As Empresas Juniores estão $70 \%$ em Instituições de Ensino Superior Públicas Federais e $40 \%$ Atuam na área de Engenharia.

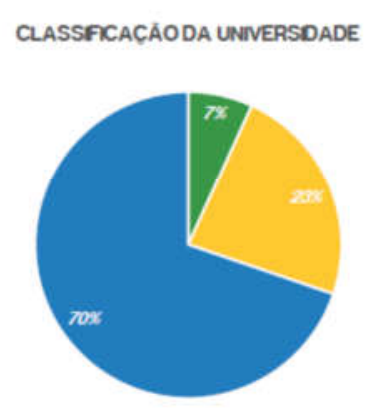

- Privada - Publica estatua - Publica federa

As empresas júniores juntas formam uma rede, chamada de Movimento Empresa Júnior. Ele é composto por todas as empresas júniores, seus núcleos regionais, federações estaduais e a Confederação Brasileira de Empresas Júniores. O Planejamento Estratégico da Rede, desenvolvido pela Brasil Júnior com o intuito de dar diretrizes e integrar essa rede, traz a missão do Movimento Empresa Júnior: formar, por meio da vivência empresarial, empreendedores. Dessa forma os 16.000 empresários júniores são incentivados a trabalhar sempre buscando práticas inovadoras em suas empresas júniores, visando projetos capazes de gerar impacto e transformação da realidade em que estão inseridos.

Em virtude do caráter voluntário dos estudantes que atuam nas empresas júniores, é possível ser cobrado pelos serviços das empresas um valor muito abaixo do que é geralmente praticado no mercado e, dessa

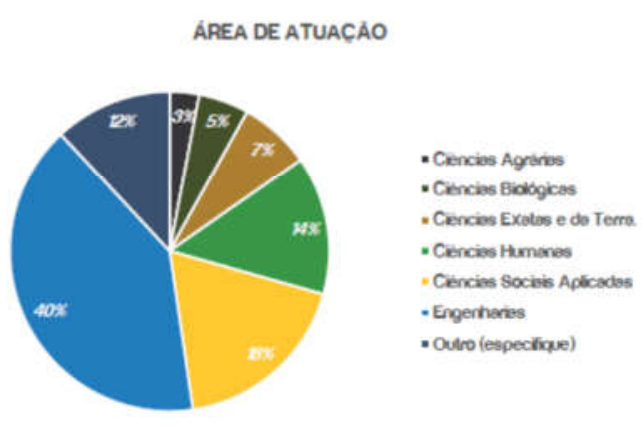

forma, tornando viável a micro e pequenos empresários contratar esses serviços. Assim, acredita-se que o Movimento Empresa Júnior impacta não somente a formação dos estudantes na universidade, mas também estimula o mercado, principalmente os micro e pequenos empresários, ao tornar os negócios mais competitivos.

Segundo o Censo \& Identidade 2016 (BRASIL JÚNIOR, 2017), cerca de 40\% dos projetos de empresas júniores foram vendidos para micro e pequenos empreendedores, sendo o restante dividido entre médias e grandes empresas, pessoas físicas e governos locais. Além disso, grandes empresas também se aproximam das empresas júniores para trabalhar atração de talentos, recrutamento e seleção, por acreditar que os acadêmicos que passam por essa experiência ainda na universidade saem de fato com um diferencial competitivo para o mercado de trabalho. Segundo o planejamento da Brasil Júnior (2017), para o 


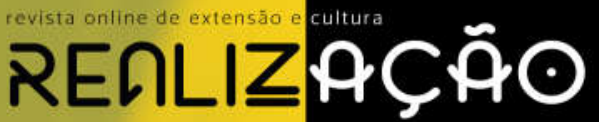

ano de 2017 a meta é que se realizem 10.000 projetos de consultoria e se fature $\mathrm{R} \$$ 18.000.000,00. A partir disso se é fomentada a vivência empresarial e se formam profissionais diferenciados para o mercado de trabalho, que ainda na universidade têm contato com projetos reais, clientes reais e metas de execução reais e lideram equipes, conforme figura abaixo.

\section{DESENTOLVIMENTO DA REDE}

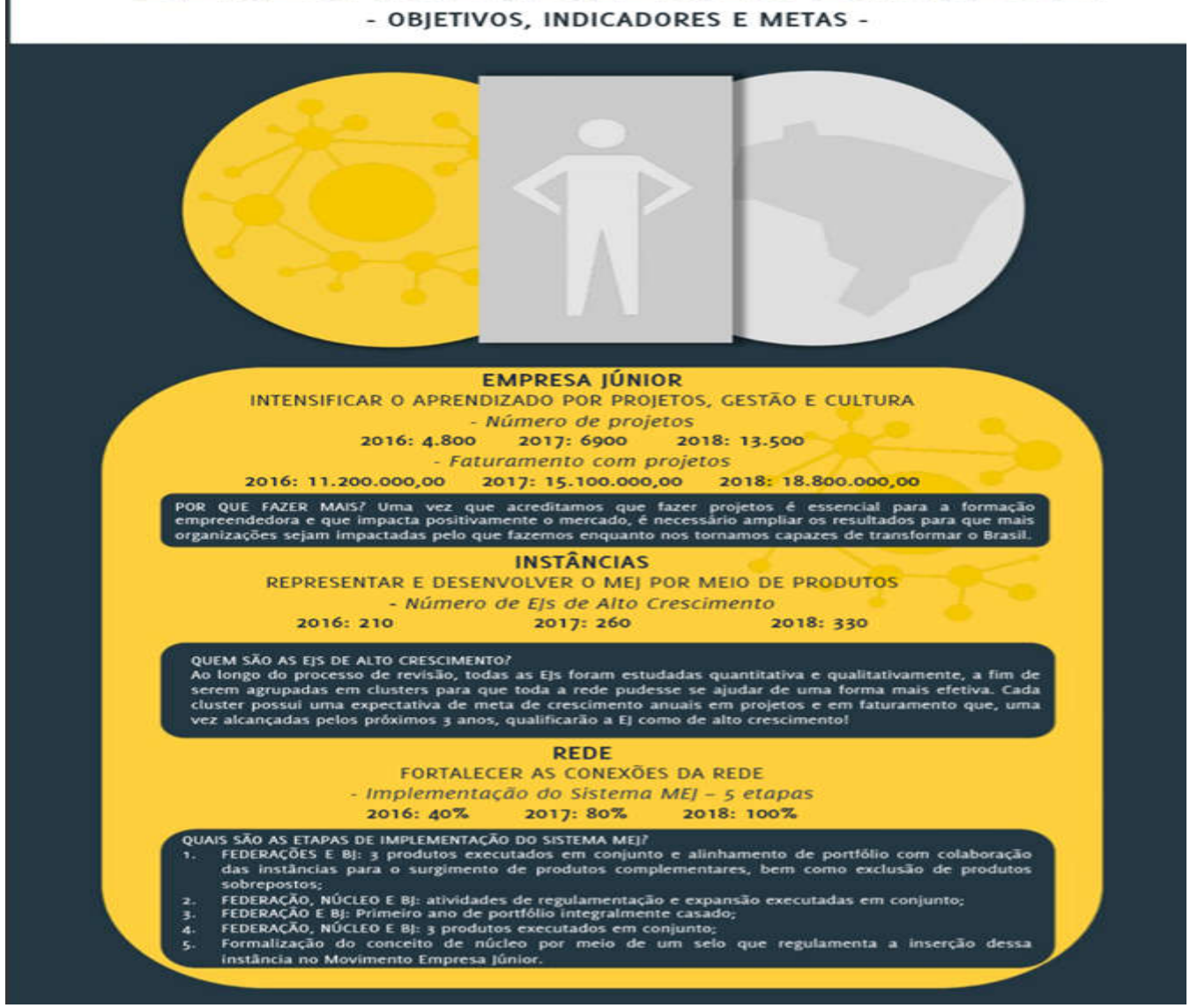

Fonte:

Planejamento Estratégico (Brasil Júnior, 2017 p. 14)

É possível perceber pontos em que o Movimento Empresa Júnior colabora diretamente para o desenvolvimento do ecossistema empreendedor brasileiro, de acordo com a perspectiva de Isenberg (2011). A esfera de suporte é atendida, por exemplo, pelas empresas júniores quando prestam serviços de consultoria para micro e pequenos empreendedores, dando o know how necessário para desenvolverem seus negócios. $\mathrm{Na}$ esfera do capital humano, através da experiência vivida na empresa júnior, são formados todos os anos milhares de estudantes com perfil empreendedor. $\mathrm{Na}$ esfera de cultura, fica em evidência a cultura empreendedora disseminada entre os jovens, as universidades e os empresários atendidos. Cabe observar como o Movimento Empresa 
Júnior, ao se consolidar nacionalmente e se expandir dentro das universidades, pode se desenvolver e impactar de forma relevante as outras três esferas do ecossistema empreendedor de Isenberg: política, finanças e mercado.

\section{A fundação da Ínteri Jr. e o início do}

\section{Movimento Empresa Júnior na UFGD}

No dia 12 de novembro de 2012, a Ínteri Jr. foi fundada pelos acadêmicos do curso de Relações Internacionais da UFGD ${ }^{1}$. Os estudantes tiveram um papel fundamental na iniciação da empresa Júnior dentro do curso, sendo atribuída a cada um a função de estudar o funcionamento e os princípios do Movimento Empresa Júnior e realizar benchmarking com outras empresas júniores da mesma área para que o estabelecimento da estrutura organizacional e das diretrizes da empresa se ajustasse da melhor forma aos objetivos do curso e de seus egressos. É interessante frisar que a fundação da empresa de Relações Internacionais dentro da UFGD não foi uma ideia que surgiu apenas em 2012, mas sim um projeto que já estava concebido no Projeto Pedagógico Curricular do curso e que ganhou força com a entrada da professora Giane Faccin ${ }^{2}$ para o corpo docente, uma vez

1 O curso de Relações Internacionais da UFGD iniciou suas atividades em março de 2009, formando seus primeiros concluintes em dezembro de 2012.

2 Bacharel em Relações Internacionais e Mestra em Ciências Sociais pela UNESP-Marília, que ela reunia a experiência de ter participado do Movimento Empresa Júnior, sendo uma das fundadoras da Empresa Júnior do curso de Relações Internacionais da UNESPMarília.

Os objetivos de sua fundação eram diversos, mas entre os mais importantes podemos destacar a inserção da UFGD enquanto instituição promotora do desenvolvimento comercial e econômico da região de Dourados e o aprendizado e capacitação dos acadêmicos em uma esfera pouco explorada dentro da sala de aula: o setor privado e empresarial. As atividades extensionistas são de extrema importância para complementar a grade curricular experimentada pela UFGD e pelos cursos de Relações Internacionais como um todo, e a Ínteri Jr. funciona como uma plataforma de ensino, pesquisa e extensão, ou seja, a empresa júnior complementa a formação acadêmica dando a oportunidade de aprendizagem ativa, através da solução de problemas reais e da execução de projetos reais, demandando que os estudantes pesquisem e aprendam sobre a execução de cada projeto.

Giane Manzeppi Faccin reúne experiência profissional em câmaras de comércio, multinacionais e com gestão executiva de projetos. Ela atuou como professora substituta do curso de Relações Internacionais da UFGD no segundo semestre do ano de 2012. 
Desse modo, a intenção da fundação da Ínteri Jr. foi promover o desenvolvimento de competências diferenciadas nos acadêmicos, por meio de experiências que eles não teriam contato em sala de aula. Essas experiências se dão em duas frentes. A frente interna, que é toda a organização interna da empresa júnior: processos de gestão de pessoas, marketing, financeiro e administrativo. $\mathrm{E}$ a frente externa, caracterizada pela efetiva execução de projetos e contato com o mercado, englobando desde como encontrar o cliente, o processo de negociação, a elaboração do contrato e a prestação do serviço de fato.

A estrutura organizacional da Ínteri vem sendo ajustada ao longo dos anos. Desde sua fundação até 2016 a empresa se dividia entre: presidência, responsável pela representação institucional; financeiro, que cuidava da documentação e fluxo de caixa; Projetos, que era a diretoria responsável exclusivamente pela execução de projetos; marketing, que era a diretoria responsável por projetar a imagem da empresa e trazer os clientes/projetos; e recursos humanos, que era responsável pela gestão de pessoas.

Após alguns anos de funcionamento seguindo este modelo, a diretoria da empresa percebeu que esta estrutura não era ideal, afinal, a empresa existe para executar projetos. Dessa forma não fazia sentido alguns poucos membros serem responsáveis por trazerem esses projetos e outros poucos membros responsáveis por executá-los. Assim, adotou-se um novo modelo organizacional mais fluido e colaborativo, de modo que mais membros tivessem contato com mais partes da empresa, a prospecção dos clientes saiu da responsabilidade exclusiva do marketing e a execução de projetos também passou a acontecer de forma integrada. Nesse sentido, o novo organograma ficou da seguinte forma: Presidência, Diretoria AdministrativoFinanceira, Diretoria de Recursos Humanos, Diretoria de Marketing e Diretoria de Área Comercial. Por fim, credita-se a essa nova estrutura real contato com os eixos da formação empreendedora por meio da vivência empresarial.

A Ínteri Jr. tem presença estratégica, pois a localização geográfica da região do Mato Grosso do Sul, fazendo fronteira com 2 países parceiros de MERCOSUL e limite com o estado de São Paulo, o mais economicamente ativo do país, gera grandes possibilidades para seus serviços voltados à internacionalização. $\mathrm{Ou}$ seja, as possibilidades que as fronteiras com outros países trazem para a produção e comercialização brasileira é tremenda e o escoamento/chegada da produção do estado de São Paulo para cá também é um ponto muito positivo para os setores em geral.

O portfólio da Ínteri Jr., dessa forma, responde às oportunidades que a localidade 
geográfica oferece, de forma a viabilizar estes processos proporcionando acesso aos micro e pequeno empresários pelos seus serviços. Os serviços ofertados são: Diagnóstico de Maturidade Exportadora, Estudo de Mercado Alvo, Consultoria de tributação, Planejamento Logístico, Análise Burocrática, Prospecção de Plataformas Online, Prospecção de Produtos Inovadores, Consultoria em Planejamento Interno para Internacionalização, Tradução, Captação de recursos internacionais. Podemos descrevêlos da seguinte forma: Diagnóstico de Maturidade Exportadora, que consiste em um diagnóstico de viabilidade mediante análise da empresa, caso seja constatado que a empresa ainda não está completamente apta, são levantados os motivos $\mathrm{e}$ as ações necessárias para a total aptidão; Estudo de Mercado Alvo, que consiste em uma análise dos países em busca do que melhor se adeque às expectativas e demandas do cliente, podendo também levantar contatos de potenciais empresas vendedoras ou compradoras do contratante no exterior; Consultoria de tributação; Planejamento Logístico; Análise Burocrática, referente aos procedimentos e documentos que serão necessários ao contratante para dar início ao processo de internacionalização desejado; Prospecção de Plataformas Online, sendo um levantamento das plataformas de vendas adequadas para a venda do produto no exterior e seus respectivos contatos;
Prospecção de Produtos Inovadores, busca de produtos inovadores no exterior para que o cliente possa comercializar no Brasil; Consultoria em Planejamento Interno para Internacionalização, referente à consultoria para organização do sistema operacional interno da empresa para que ela esteja apta a lidar com os processos e demandas da internacionalização; Captação de recursos internacionais, consiste na viabilidade de recursos financeiros de editais disponíveis (de empresas, governos, organizações, entre outros) para instituições sem fins lucrativos ou com projetos sociais; e por fim, Tradução.

A implantação de uma empresa júnior em um curso contribui para a função da Universidade em ser um agente de impacto social, a partir do momento que estes acadêmicos passam a realizar seus projetos. Dessa forma extrapola o papel de impacto no ecossistema e atinge também uma importante questão, a base pedagógica e o atual modelo de aprendizagem do ensino superior brasileiro. Junta-se a isso a extensão da sala de aula configurada pela empresa júnior, ambiente no qual através da experiência o estudante se capacita e se diferencia dos demais acadêmicos do curso que não passam por essa vivência, pois oferece ao mercado de trabalho a experiência prática de conceber projetos ainda em estágios iniciais de sua carreira. 
Sendo a primeira empresa júnior da UFGD, após sua fundação, a Interi Jr. e seus membros se tornaram responsáveis por referenciar o movimento empresa júnior e propagar o conceito para os demais acadêmicos dentro da universidade. Após cerca de três meses de existência, a Interi Jr. se tornou referência não só para os demais cursos da UFGD, mas também foi considerada a melhor EJ do estado do Mato Grosso do Sul pela Brasil Júnior. Fato esse que deu mais força e incentivo para seus membros continuarem trabalhando ainda mais no desenvolvimento da empresa. Logo após, outras duas empresas júniores se juntaram à Ínteri Jr. no papel de propulsoras do movimento no estado, sendo estas três as fundadoras da Federação de Empresas Júniores do Mato Grosso do Sul (FEJEMS): a Terra Fértil Empresa Júnior e a Factiva Júnior, respectivamente empresas de Agronomia da UFGD e de Engenharia de Produção da UFMS, campus da cidade de Três Lagoas.

\section{Movimento Empresa Júnior no Mato Grosso do Sul}

O Movimento Empresa Júnior no Mato Grosso do Sul vem apresentando um crescimento exponencial, e a fundação da FEJEMS foi essencial nesse processo. Ela conectou as três empresas júniores fundadoras e com isso deu legitimidade representativa para o movimento no Estado.
Cada uma dessas empresas atuou para estimular outros acadêmicos a fundarem novas empresas júniores, para que mais universitários tivessem a oportunidade de acessar uma formação acadêmica diferenciada.

Segundo o mapeamento mais recente obtido com a Federação, atualmente o Estado conta com cerca de 36 empresas júniores por todo o Estado, contabilizando mais de 410 universitários que passaram por uma empresa júnior desde 2013. Ademais há um potencial de crescimento latente, pois não são todas as universidades do Estado que possuem uma empresa júnior como projeto de extensão. Nesse sentido, a Federação de empresas júniores do MS vem fazendo um trabalho de fomento a novas iniciativas júniores, bem como respaldando a regularização das empresas júniores existentes, de forma a garantir segurança jurídica e legalidade, para que o movimento siga se fortalecendo na região.

Assim como o movimento empresa júnior, que ainda é muito recente e incipiente no Estado, o ecossistema empreendedor no Mato Grosso do Sul ainda está em formação, com várias outras instituições como a FIEMS, o SEBRAE, secretarias municipais e estaduais, câmaras de comércio, lançando ações para aumentar o horizonte de oportunidades do empreendedor local, que é um tipo de economia diferente da economia 
tradicional do estado. Então todo esse processo de expansão se conecta com as expectativas de desenvolvimento do estado através das consultorias e serviços prestados pelas empresas júniores para os setores econômicos mais produtivos do estado, que são o agronegócio, como fonte principal, o processamento de grãos e carnes e o turismo ambiental.

Além dos serviços de internacionalização que a Ínteri Jr. oferece e foram descritos anteriormente, o Movimento Empresa Júnior tem muito a contribuir com o ecossistema local através de outras áreas. Até agora, as Empresas júniores existentes conseguiram se inserir no mercado através da execução de projetos de diversos portes e para públicos diversificados, como alguns casos listados a seguir.

A Empresa Júnior de agronomia, a Terra Fértil, se inseriu no mercado através do seu famoso "dia de campo", que consiste na condução de plantações de variedades de produtos das empresas para demonstração e/ou experimentação, de forma a conectar as empresas a outros clientes e aos estudantes, proporcionando às empresas obtenção de vantagens e aos estudantes adquirem conhecimento. Ou seja, o intuito principal é mostrar o portfólio da empresa para os clientes e também proporcionar este contato prático para os estudantes.
Já as áreas de engenharia têm um campo muito vasto, pois englobam as áreas de civil, elétrica, computação, produção, alimentos, energia, física e ambiental, divididas em 6 empresas dessas áreas, das quais quatro estão localizadas em Dourados, uma em Campo Grande e uma em Três Lagoas. Os serviços que elas já prestaram são diversos, focados principalmente em realizar projetos arquitetônicos, elétrico e de cabeamento possibilitando a abertura de novos negócios para micro e pequenos empresários.

Também se destacam atuando na área de engenharia ambiental, onde regulamentaram um hospital de acordo com as normativas vigentes na cidade de Campo Grande. Por sua vez, a Ejipta, empresa júnior de engenharia de alimentos, executou no ano de 2015 um projeto para a Florestas Brasileira Indústria e Comércio de produtos florestais e agrícola S.A no município de Itapecuru Mirim /MA. Este projeto teve por objetivo consultorias laboratoriais e técnicas em processos de avaliação tecnológica da farinha e do óleo de babaçu e desenvolvimento e aceitação sensorial de produtos à base de farinha de babaçu. Podemos citar também outros clientes outrora atendidos pelas EJs dessa área, empresários do ramo alimentício atendidos em licenciamento, profissionais da construção civil que buscam os chamados 
projetos complementares, donos de pousada que foram atendidos em licenciamentos, além dos mais diversos segmentos em busca de sites e desenvolvimento mobile para expandir suas vendas e controle.

Outras áreas que também são contempladas até o momento pelas empresas júniores existentes são: direito, com estruturação societária jurídica, elaboração de pareceres, elaboração e revisão de documentos jurídicos, capacitação jurídica, acompanhamento de processos judiciais e registro de marcas e patentes; farmácia, com treinamentos na área da saúde, higienização de alimentos e segurança no trabalho, elaboração de tabelas nutricionais, procedimentos operacionais padrões e boas práticas para a área de saúde e alimentos, etc.

Acrescentamos a essa lista outras empresas que ainda não estão completamente asseguradas juridicamente por falta de documentos e não são tão próximas da rede, mas que já podem executar projetos, podemos citar as áreas de: nutrição, administração, comunicação social, engenharia de aquicultura, engenharia agrícola, ciências sociais, turismo, ciências contábeis, economia, psicologia, biotecnologia e gestão ambiental. Ou seja, fica claro que apesar do movimento ser muito jovem no estado, seu potencial de crescimento e bastante significativo.
Quando analisamos o Plano de Desenvolvimento Institucional da UFGD (2013-2017) por exemplo, analisamos que as diretrizes de uma empresa júnior seguem as diretrizes do PDI, pois nele é expressa a vontade de "ampliar a produção de conhecimento no interior da Universidade, articular tal produção com as demandas do mundo produtivo. Ou seja, ampliar nossas relações com os grupos empresariais e com as economias sociais e solidárias da Região (Centro-Oeste, de Fronteira) e do País." (pg.27). Observamos uma convergência de propósitos da empresa júnior e intencionalidades da própria Universidade. Nesse sentido são largos os passos para que a Universidade de fato gere impacto social no ecossistema local. Verificamos inclusive que as empresas júniores possuem um potencial de inserção muito maior ao que elas realmente exploram/estão inseridas até o momento, pois outras vertentes extensionistas da Universidade atuam no setor sucroalcooleiro, na indústria de alimentos e na cadeia produtiva do pescado; setores nos quais as empresas júniores ainda não conseguiram se inserir de forma efetiva na região.

\section{Considerações finais}

Concluímos que o perfil de economia tradicional do estado não deve ser tomado como fator determinante da economia regional, é preciso buscar novas formas de 
economia para que o estado siga se desenvolvendo em áreas que ainda carecem de exploração. Com o movimento empresa júnior essa ideia de desenvolvimento é potencializada, pois compartilha a crença que para transformara realidade social é preciso gerar microrrevoluções em cada ecossistema local. Isso não significa que as empresas júniores não atendam empresas grandes e consolidadas, significa que além dessas grandes empresas terem acesso a esses serviços, os mesmos serviços estão ao alcance dos demais empreendedores, cuja relação pode ser explorada em virtude do perfil dos serviços e dos valores estabelecidos.

A profunda crise econômica e política que o Brasil enfrenta com certeza deixa um cenário pessimista para os empreendedores, $o$ medo de arriscar, o medo de sair da zona de conforto e dar errado assombra os brasileiros, mas acreditamos que a saída dessa situação virá através do fortalecimento da nossa própria economia. O Movimento Empresa Júnior tem a finalidade de ajudar estes empreendedores a explorarem novos horizontes para suas empresas, o que no caso específico da Ínteri Jr. trata de levar sua produção ou serviço para fora ou traze-los de lá para cá. Com a consultoria internacional júnior, a economia regional pode passar a explorar novas possibilidades de forma sustentável e assistida, para que o potencial da empresa não se limite a limites geográficos.

Se o estado não apostar em novas formas de movimentação da economia e de geração de valor para a cadeia produtiva e de serviços, ficará dependente das mesmas variáveis históricas. Empreender e ousar em um novo negócio não é um mistério, é uma combinação de "três competências básicas: habilidade gerencial, capacidade empreendedora e logística operacional" (CAVALCANTI E TOLOTTI, 2012, pg. 07). O ponto é que, o empresário/empreendedor não precisa necessariamente possuir essas três competências, pois através das consultorias júniores ele consegue tirar sua ideia do papel com o auxílio e "know how" dos universitários.

Segundo Glauco Cavalcanti e Márcia Tolotti, consideramos que crise e risco têm em comum a tensão, mas a percepção desses riscos muda dependendo da forma como eles são apresentados. Nesse sentido é interessante compartilhar a teoria de lócus de controle. Essa teoria foi formulada por Julian B. Rotter em 1966 (DELA COLETA, 1979), que trata sobre a maneira que os indivíduos atribuem a responsabilidades sobre os eventos que ocorrem em suas vidas. Existem pessoas que possuem o lócus de controle externo, que atribuem a fatores externos e que elas não podem controlar a responsabilidade sobre os eventos, e pessoas que possuem 
lócus de controle interno, ou seja, que puxam para si a responsabilidade sobre os eventos. Por exemplo, uma pessoa saiu de casa sem guarda-chuva, choveu e ela se molhou, essa pessoa pode encarar a situação de duas formas: a culpa é do tempo que mudou e ela se molhou, pois não imaginava que choveria, ou a pessoa assumir que poderia ter olhado a previsão do tempo antes de sair de casa para evitar esta situação.

O que a exposição desses dois tipos de perfil significa? Significa que segundo o movimento empresa júnior, um empreendedor comprometido e capaz não é aquele que apenas sabe como executar a ideia, é aquele que vai lá e faz! Ou seja, é possível encarar os tempos de crise e nebulosidade econômica de duas formas, que se relacionam com o lócus de controle, ou culpar a crise econômica pela estagnação econômica de determinado ecossistema, ou deixar de ser telespectador do próprio negócio e se tornar agente de mudança tirando do papel as ideias inovadoras/melhorias que só o movimento empresa júnior pode proporcionar por um valor acessível.

\section{Referências}

BRAGA MARTES. A. C. Weber e Schumpeter: a ação econômica do empreendedor. Revista de Economia Política. v. 30, n.2, São Paulo, 2010.

BRASIL JUNIOR. Censo \& Identidade 2016. São Paulo: Confederação Brasileira das Empresas Júniores, 2017. Disponível em: http://brasiljunior.rds.land/censo-identidade-relatorio2016. Acesso em 06 de setembro de 2017.

CAVALCANTI, G.; TOLOTTI, M. Empreendedorismo, decolando para o futuro: as lições do voo livre aplicadas ao mundo corporativo. Rio de Janeiro: SEBRAE, 2012.

DELA COLETA, J. A. A escala de lócus de controle interno-externo de Rotter: um estudo exploratório. Arquivos Brasileiros de Psicologia, ISOP/FGV, v.31, n.4, 1979.

ENDEAVOR BRASIL. O que é Empreendedorismo? Disponível em: $<$ https://endeavor.org.br/tudo-sobre/empreendedorismo/> Acesso em 20 nov.2017.

ISENBERG. D. The Entrepreneurship Ecosystem Strategy as a New Paradigm for Economic Policy: Principles for Cultivating Entrepreneurship. May 11, 2011.

MARTINELLI, J. Locus de controle. Disponível em: < http://www.duomoeducacao.com.br/Lideranca/locus-de-controle.html>. Acesso em 20 nov. 2017.

PINCHOT III, G. Intrapreneuring: why you don't have to leave the corporation to become an entrepreneur. New York, Harper \& Row, 1985. 
SCHUMPETER, J. Capitalismo, Socialismo e Democracia. Rio de Janeiro: Editora Fundo de Cultura, 1961.

UFGD. Plano de Desenvolvimento Institucional 2013-2017. Pró-Reitoria de Avaliação e Planejamento de Universidade Federal da Grande Dourados, 2014. Disponível em: http://files.ufgd.edu.br/arquivos/arquivos/78/ADMINISTRACAO-

UFGD/PDI\%20UFGD\%202013_2017.pdf. Acesso em: 06 de setembro de 2017. 